\title{
Three-Phase Rectifiers with Current Compensation Schemes - Part I: Passive Circuits
}

\author{
Marco Rivera \\ Faculty of Engineering \\ University of Talca \\ Curico, Chile \\ marcoriv@utalca.cl \\ Patrick Wheeler \\ Dept. of Electrical \& Electronic Engineering \\ The University of Nottingham \\ Nottingham, UK \\ Pat.Wheeler@nottingham.ac.uk
}

\author{
Daniel Faundez \\ Faculty of Engineering \\ University of Talca \\ Curico, Chile \\ dfaundez12@alumnos.utalca.cl \\ Jose A. Riveros \\ Faculty of Engineering \\ University of Talca \\ Curico, Chile \\ jriveros@utalca.cl
}

\author{
Johann Kolar \\ Power Electronic Systems Laboratory \\ ETH Zurich \\ Zurich, Switzerland \\ kolar@lem.ee.ethz.ch \\ Sergio Toledo \\ Faculty of Engineering \\ University of Talca \\ Curico, Chile \\ stoledo@utalca.cl
}

\begin{abstract}
Three-phase rectifiers are widely used in several applications. The main feature desired in these power converters is a satisfying regulation of dc output voltage/current, but this ought to be achieved with high quality ac currents and unitary power factor. The most conventional schemes have unidirectional power flow and a compensation of the ac-side current should be implemented in high-performance systems. A small part of the power converted can be employed to enhance the characteristics in the mains side by using additional passive, active or hybrid circuits. This paper is the first of two parts, where the technology of ac-dc three-phase power converters with compensation techniques to attain ac currents with ohmic behaviour is reviewed. This part reports the passive networks used for this aim, describing the most popular topologies and features.
\end{abstract}

Index Terms-Ac-dc power converters, pasive current compensation

\section{INTRODUCTION}

The conventional three-phase diode bridge rectifiers are still one of the most used ac-dc power converters, because they are the most affordable and straightforward topology. Nevertheless, its operation is characterised by undesired features such as high ac current distortion that imply also a conversion with poor power factor. Passive and active filters are commonly connected in the ac-side of these rectifiers to overcome these issues. However, current injection schemes were established as the proposal to attain the highest efficiency with widespread employment in aerospace applications [1]. The compensator can comprise either passive, active or hybrid circuits. This paper deals with the first method, and different developments are reviewed describing their main characteristics.

Passive filters are the conventional solution to mitigate the low-order current harmonics generated with rectifiers. They are in essence tuned banks of LC filters that could be connected in series or shunt configurations to damp or drive to ground the undesired current harmonics [2]. Series filters present a high impedance path at the current harmonics and might cause input voltage distortion to the rectifier [3]. This topology is characterised by large size components, reducing its potential for compact applications. On the other hand, the shunt connection works as a current sink to the harmonic components through a low impedance circuit to ground. This configuration provides a promising potential, but the design is more complex considering that the association with the inaccurate and variable power source impedance affects its performance and could cause damages due to resonance [4].

Active filters are based on power converters that inject current harmonics to the grid with the same and opposite phase than those generated by the rectifier [5]. These are a broad spread solution within the industry and the modern developments present high-performance, small size and flexibility to the detriment of more complex architecture and control [6]. A current control is mandatory in this proposal. This usually injects a reference current harmonic in the mains side with a constant pattern, while the amplitude depends on the nonlinear rectifier's load.

An advancement in the filter's architecture is the combination of the two previous topologies to maintain the ac power source reliability. This is known as hybrid power filters that comprise passive and hybrid stages [7]. The passive part is used to mitigate specific current harmonic components, while the active component controls the wide range of remaining frequencies. This combination reduces the size and weight of the passive filter as well as the cost of the active one.

Three-phase rectifiers with low ac current distortion have been classified as line-commutated (passive control) and selfcommutated (active control), while the hybrid methods can be considered as one sub-classification between these two groups [8]. The passive schemes employ multi-pulse rectifiers. They are preferred for high-power systems with low dynamic and where the quality of the current is not a priority [8]. An additional dc-dc stage (boost, buck or buck-boost) is usually implemented at the $\mathrm{dc}$-side to provide the capability to operate 


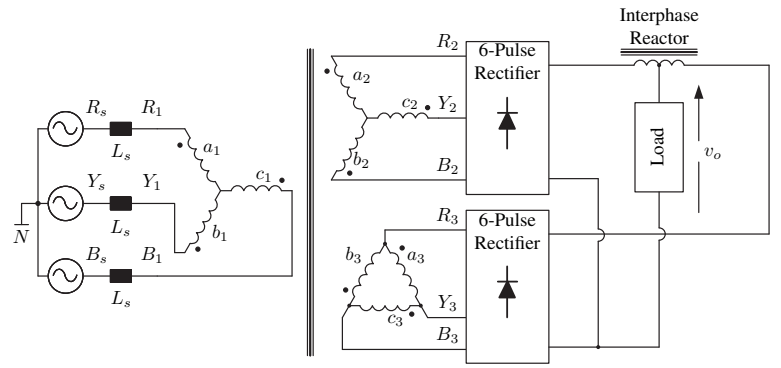

Fig. 1. 12-pulse rectifier using a double-wound transformer.

in a wide range and control the power flow.

The drawbacks of the lastly described rectifier are the complex control strategy and the reduction of the efficiency due to the power limits of the dc-dc stage. An alternative to avoid the use of an extra power converter are passive ac current injection topologies [8]. This circuit uses only a small portion of the energy processed by the rectifier. The banks of passive elements cover only specific operation points, while the design of high-order functions is highly complex [9]. The use of large components and the narrow operation range can be some of the issues evidenced in this proposal. TThe active network mitigates this shortcoming at the expense of far more expensive and involved schemes. Again, these disadvantages can be lessened with the hybrid technology.

This work surveys three-phase power rectifiers with ac current compensation focused in aerospace applications. The report has been organized in two parts. This paper reviews the passive injection methods, whereas the active and the hybrids current injection are explored in the second part [10].

\section{Three-Phase Rectifier with Passive Network}

The most popular and promoted topologies of multi-pulse power rectifier with passive injection network are presented as follows.

\section{A. 12-Pulse Rectifier with Double-Wound Transformer}

This development employs two conventional six-pulse rectifiers supplied by a $\mathrm{Y}-\Delta-\mathrm{Y}$ double secondary wound transformer to attain two three-phase ac sources electrically shifted by $30^{\circ}$ [11], as depicted in Fig. 1. Notice that the load ought to be supplied using an interphase reactor and the connection lessens the 5th and 7th current harmonics in the mains side. The transformer isolates the systems but this is large and heavy for high-power applications.

\section{B. 12-Pulse Rectifier Fed by Autotransformer}

This reported topology uses a dc current source converter in aerospace applications [12-14]. The configuration is shown in Fig. 2, and is capable of reducing the galvanic component of the previous scheme. This allows lower weight and price along with higher efficiency. On the other hand, two interphase inductors are required for the autonomous operation of the six-pulse rectifiers. The 5th and 7th order current harmonics are mitigated due to the autotransformer connection and the $120^{\circ}$ of conduction of the diodes, respectively. The array of

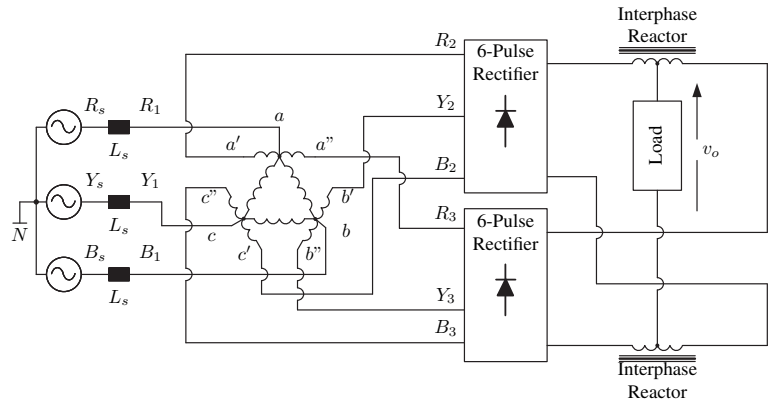

Fig. 2. 12-pulse rectifier with autotransformer.

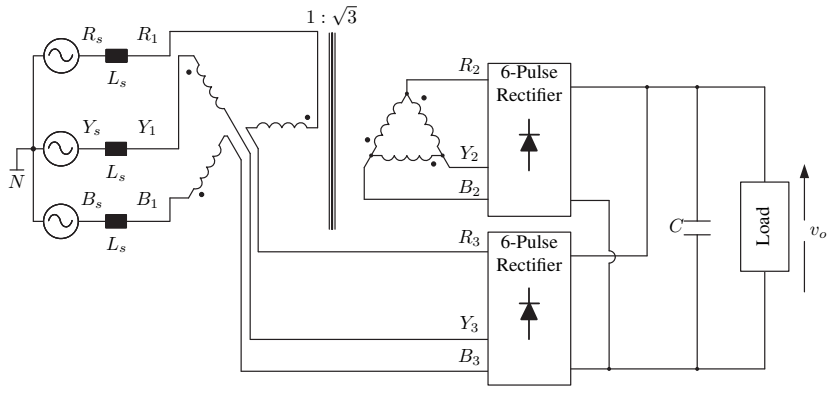

Fig. 3. 12-pulse rectifier using a transformer primary in series
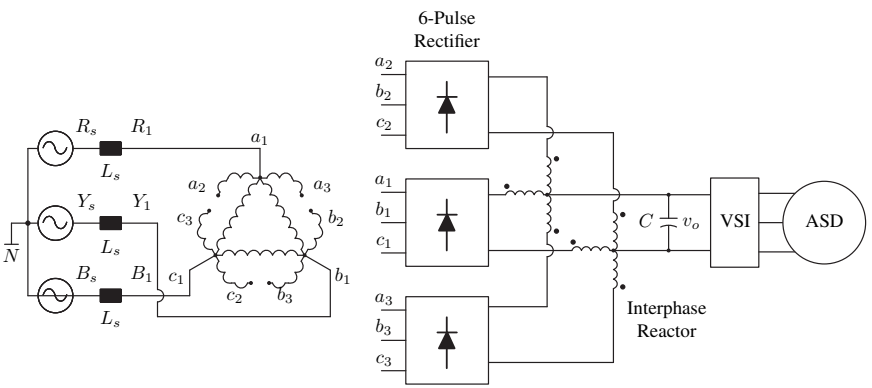

Fig. 4. 18-pulse diode rectifier using an autotransformer and winding configuration of interphase reactor

the autotransformer provides same current sharing, conducting through equal leakage reactance in series within the line of the rectifier's bridge.

\section{12-Pulse Rectifier with Transformer Primary in Series}

This ac-dc scheme is compounded by a single-wound Y- $\Delta$ transformer and two six-pulse rectifiers [11]. The secondary windings feed the first bridge, while the second is connected to the ac power source in series with the primary windings (see Fig. 3). The transformer can be dimensioned at half of the total power by using this arrangement, but the system is not isolated from the ac-side. This configuration can operate either as a current or on a voltage source multi-pulse rectifier. The output load is fed by using a storage capacitor and the 12-pulse current pattern is achieved in the ac-side.

\section{18-Pulse Rectifier Using an Autotransformer and Winding Configuration of Interphase Reactor}

This proposal is an extension of the 12-pulse ac-dc converter with autotransformer, previously described in subsection B, by 
appending an additional three-phase rectifier (see Fig. 4).

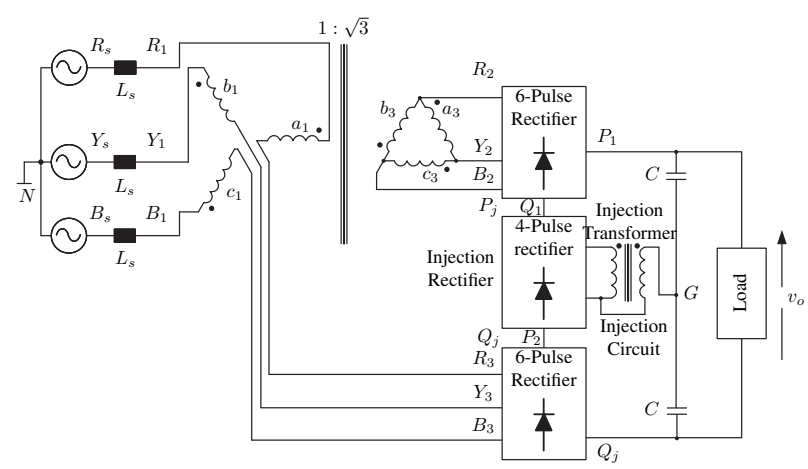

Fig. 5. 24-pulse rectifier with passive ripple injection

The three six-pulse rectifiers are arranged as depicted in Fig 4. This is in essence a current source rectifier, which does not need the interphase transformer. The set of six-pulse rectifiers operate in discontinuous conduction mode. Then, at every time only two bridges are activated, because they do not share the load current. Consequently, the diodes must support the full load current $[12,13]$. This arrangement allows the mitigation of the 5th, 7th, 11th and 13th order harmonics to attain a clean response in the main side.

\section{E. 24-Pulse Rectifier with Passive Ripple Injection}

This topology applies modifications to the 12-pulse architecture with a primary transformer in series to achieve low ac harmonic current and similar input voltage levels to a 24pulse rectifier [15]. The three-phase rectifiers are connected in series (current-fed rectifiers) through the passive network as is depicted in Fig. 5. The transformer turn ratio warranties same current magnitude for both six-pulse bridges but electrically shifted by $30^{\circ}$. The injection circuit is a single-phase full-wave rectifier exposed to the full current and connected to a small transformer which is linked to the mid-point of the dc-bus and operates at six times the supply frequency (ripple main component). Since the primary winding of the transformer is connected in series with one six-pulse rectifier, the converter is not isolated from the power source neither the output voltage is controlled with the primary-secondary turn ratio $[16,17]$.

The scheme employs only passive components with lower number of components, along with a simpler and lighter transformer compared to other designs capable of achieving 24-pulse pattern. This feature makes the proposal suitable for aerospace applications.

\section{F. 24-Pulse Current-Source Rectifier using DC Ripple Injec- tion Techniques}

This ac-dc power converter is an adaptation of the standard double-wound 12-pulse rectifier (subsection A) to achieve a 24-pulse operation by using an extension of the DC ripple re-injection technique [18]. This topology is summarised in Fig. 6. The passive injection network is composed by two capacitors to block the DC voltage components of the threephase rectifiers, two injection transformers that operate at the

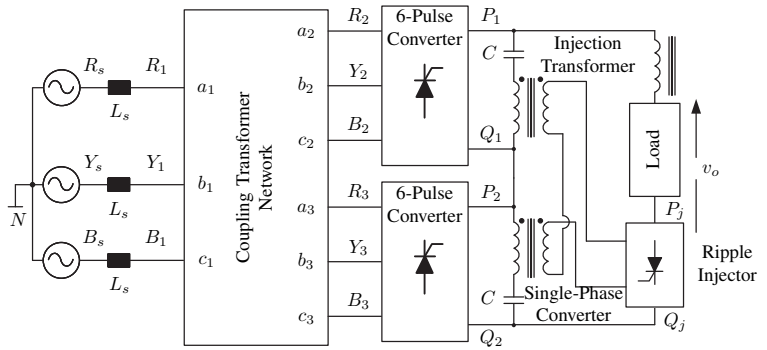

Fig. 6. 24-pulse current-source-converter using a current ripple injector in series with the load

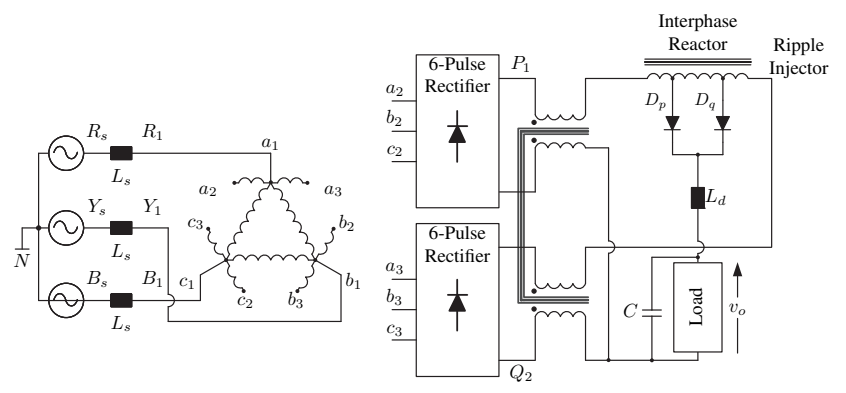

Fig. 7. 24-pulse rectifier with ZSBT

ripple frequency (six times the fundamental) and a singlephase controlled full-wave bridge.

The ripple voltage of the three-phase bridges is the alternating input of the injection transformers. The six-pulse rectifiers inject this component into their respective primary auxiliary windings to re-inject two square current waveform at six times the fundamental frequency and shifted by $30^{\circ}$. Thus, the secondary output voltage is a 12-pulse waveform, that in combination with an appropriate transformer turn ratio value and firing angle control generates a 24-pulse waveform in the output of the ac-dc converter.

\section{G. 24-Pulse Rectifier with Zero-Sequence Blocking Trans- former (ZSBT)}

The scheme seen in Fig. 7 was introduced in $[19,20]$. The architecture of the 12-pulse topology with an autotransformer is modified adding a ZSBT, and the pulse multiplier current injector technique described in the previous subsection is the passive network. The ZSBT ensures independent operation of the six-pulse diode rectifiers and provides a high impedance path to the zero-sequence current. This allows $120^{\circ}$ conduction and equal current sharing by the two three-phase rectifiers in a more accurate manner than the one attained by using extended delta transformers. The current injector circuit operates with the same principles previously explained to achieve the characteristics of a 24-pulse pattern in the ac power source lines.

\section{H. Harmonic Reducing 24-Pulse Rectifier}

This proposal adapts the conventional series connected 12pulse rectifier to attain a similar structure to the 24-pulse with passive ripple injection scheme. The shifted three-phase voltages are generated by using a $\mathrm{Y}-\mathrm{Y}-\Delta$ transformer (see 


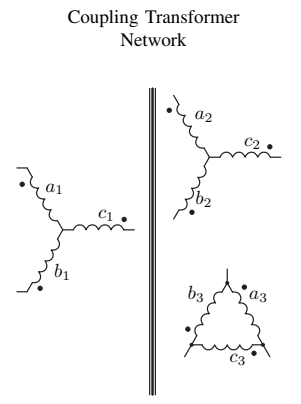

Fig. 8. Coupling transformer network of the harmonic reducing 24-pulse rectifier

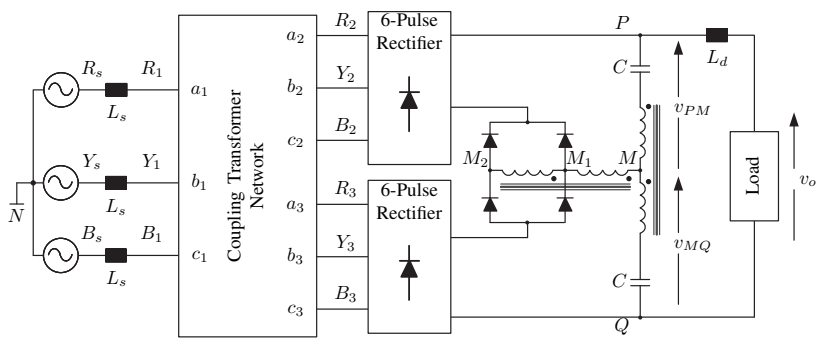

Fig. 9. 24-pulse rectifier with auxiliary circuit (harmonic reducing)

Fig. 8) to supply the diode bridges connected in series as indicated in Fig 9.

The passive network is divided in two parts: an auxiliary rectifier and a dc splitting circuit. The single-phase bridge (in series with three-phase rectifiers) injects current into the $\mathrm{P}$ and $\mathrm{Q}$ rails of the dc-link increasing to 24-pulse the output voltage behaviour. The ac input of this auxiliary bridge is fed by the left-side of one autotransformer built with an appropriate turn ratio, while the right-side is linked to the tap of a second autotransformer located in the splitting circuit. The latter, halves the output voltage (being $M$ the mid-point) and the current injected between the $\mathrm{P}$ and $\mathrm{Q}$ rails to balance the sharing currents of the two six-pulse rectifiers.

\section{24-Pulse Current-Source-Converter Using an Inter-Phase Reactor as Part of the Ripple Injector}

This architecture is a parallel 12-pulse rectifier, while the passive circuit is configured with a tapped transformer and two controlled rectifiers [21], see Fig. 10. The same principles are applied and the 12-pulse voltage ripple is employed to generate a pulsating current that is fed back to the dc-side using the interphase transformer. The 24-pulse operation is achieved injecting appropriately six times frequency currents (by controlling the firing angles of the thyristors).

\section{J. 36-Pulse Voltage Rectifier With Self-Switched Double- Bridge and Parallel 12-Pulse Converter}

The parallel connection of 12-pulse rectifier improves its performance by injecting the voltage ripple in the dc load, and it could achieve 24-pulse performance as indicated in subsection G. Further enhancements are attained with the use of self-switched double-bridge schemes, which have multilevel

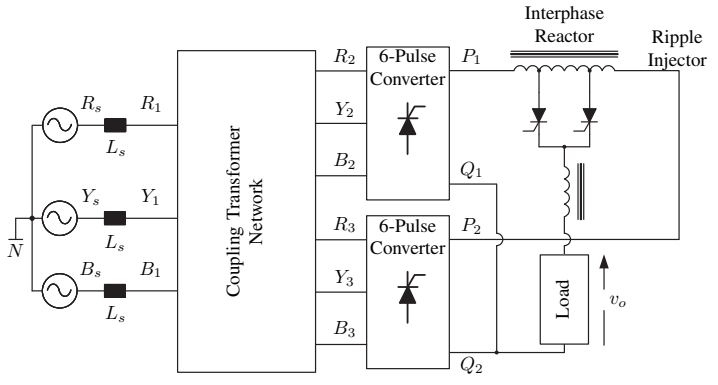

Fig. 10. 24-pulse current-source-converter using an inter-phase reactor as part of the ripple injector

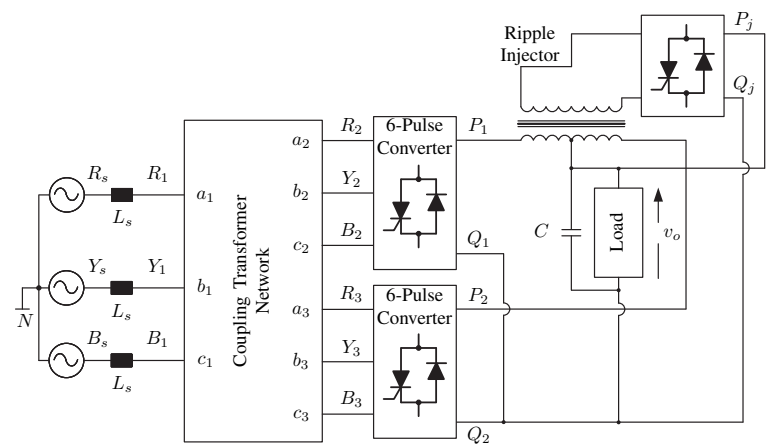

Fig. 11. 36-pulse voltage-source-converter using multilevel double-bridge.

operations [22]. One proposal that follows this principle is analysed in Fig. 11. The conventional six-phase rectifier is replaced by double bridges and an interphase transformer along with a GTO-diode single-phase bridge in the injection circuit. This topology produces multilevel waveforms and 36pulse characteristic on the ac-side.

\section{K. 36-Pulse Voltage Rectifier With Self-Switched Double- Bridge and Series 12-Pulse Converter}

This rectifier is a variant of the previous proposal, connecting the 12-pulse configuration in series as depicts Fig. 12. The passive circuits injects current using a transformer linked to the mid-point of the dc-bus to exploit the 12-pulse voltage ripple and generate a 36-pulse operation with low ac current distortion. The complete design of the galvanic components and the firing angle strategy is reported in [23].

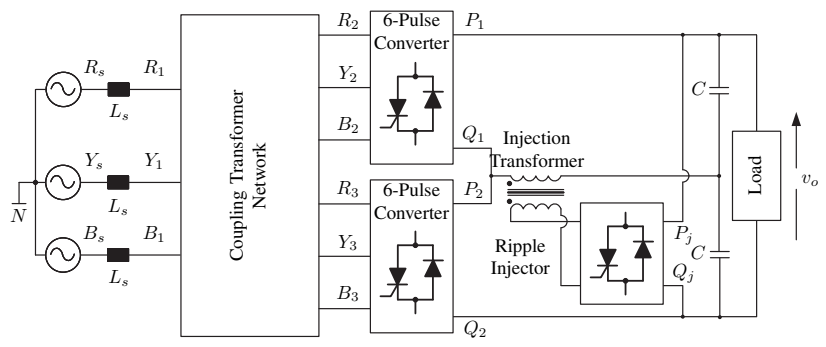

Fig. 12. 36-pulse voltage-source-converter using the voltage ripple injection method applied to the 12-pulse converter in series 


\section{36-Pulse Converter with Coupling Transformer Network}

A 36-pulse design with a simple circuity was proposed in [24]. Figure 13 presents this scheme. Notice that the use of three thyristors in the injection circuit is the main difference with respect to the conventional double-wound transformer 12-pulse configuration of subsection $\mathrm{A}$. The design of the interphase autotransformer in combination of the firing angle strategy of the thyristors make possible the 36-pulse operation.

\section{Multi-Pulse Self-Commutated Current Source Rectifier}

The architecture of this power rectifier is drawn in Fig. 14. It is based on the multilevel parallel 12-pulse configuration of subsection L. The coupling transformer network is al doublewounded Y-Y- $\Delta$ (Fig. 15) with primary-to-secondary turns ratios of 1 and $1: \sqrt{3}$, respectively. The multilevel DC current injection uses a GTO or IGCT switched multi-tap interphase reactor. Significantly low polluted ac currents are achieved with this topology and the passive input filter can be avoided.

\section{N. Generalised Pulse Multiplication for Series Connected Converters}

The concept of series connected rectifier with $n$-pulse using straightforward circuits has been generalised in [25]. The scheme considered for the pulse re-injection circuit are multiple single-phase full-wave bridges as well as thyristors that injects a pulsating current in the dc-side using the voltage ripple to improve the ac current characteristics. For instance, the single-phase full-wave bridge generates a current which doubles the voltage ripple frequency. Then, this configuration obtains $2 k$-pulse operation if the series rectifiers are of $k$-pulse. This can be complemented by adding a thyristor to multiply the frequency by three, while two bridges attain a factor of four (two secondary windings are also needed in the interphase transformer for this purpose). Again, by adding a thyristor to the last design, the pulsating current is injected at five times the series association ripple frequency, and so on.

Some examples of this proposal are presented as follows. The simplest case is the development of a 12-pulse rectifier without double-wound transformer. A six-pulse can be adapted with the passive network of this approach to operates as 12pulse configuration, see Fig. 16. The secondary windings of the transformer ought to be configured in $\mathrm{Y}$ connection to inject the ripple voltage with respect to the common-point. The

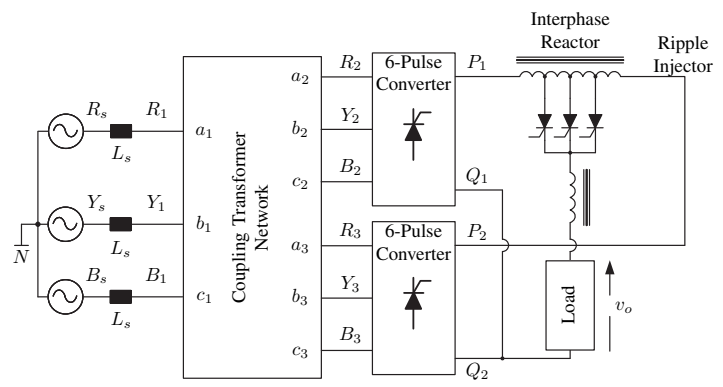

Fig. 13. 36-pulse converter with coupling transformer network

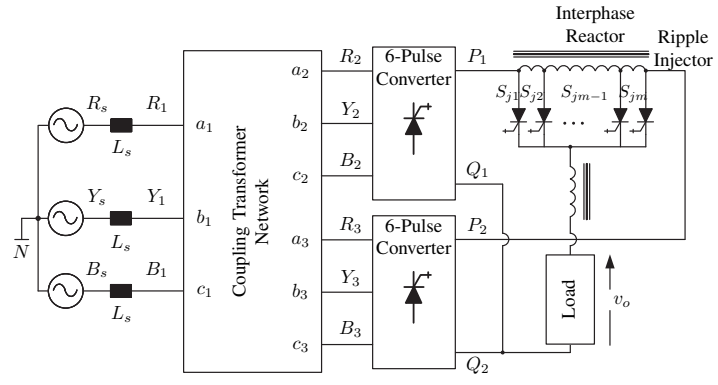

Fig. 14. Multi-pulse self-commutated current-source-rectifier

Coupling Transformer Network

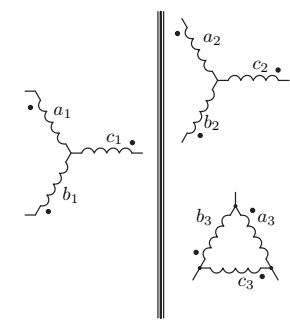

Fig. 15. Coupling transformer network for the multi-pulse re-injection converter

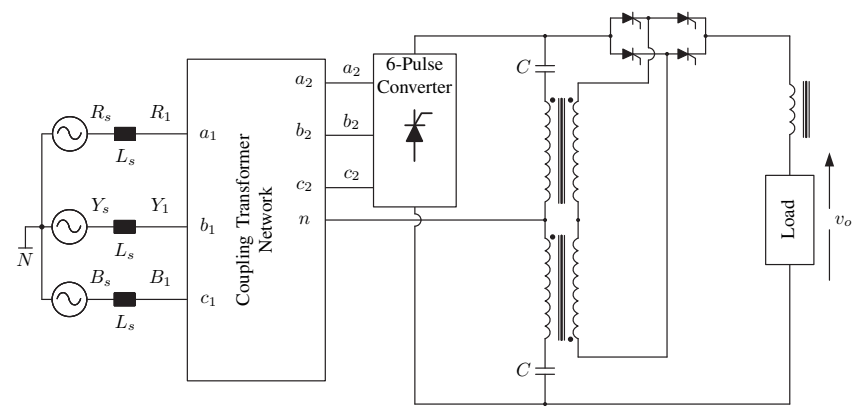

Fig. 16. Six- to Twelve-pulse converter.

operation can be extended to 24-pulse by using a two singlephase rectifier and a two-secondary transformer as indicated in Fig. 17. The subsequent scheme is the 12- to 36-pulse presented in Fig. 18. The power source is coupled with a $\Delta$-Y$\Delta$ transformer, while the 12-pulse voltage ripple generates the pulsating current with a factor of three. The auxiliary circuit is composed by a single-phase bridge and a thyristor.

\section{Conclusions}

In this paper, the first part of the review of a high-power rectifier with low harmonic energy concentration in the acside was presented. The main schemes developed with passive injection circuit have been surveyed. The configurations are based on conventional six-pulse diode bridges simplifying the control requirements and providing competitive price to the different proposals. However, the coupling transformer and passive elements imply bulky and heavy power converters. 


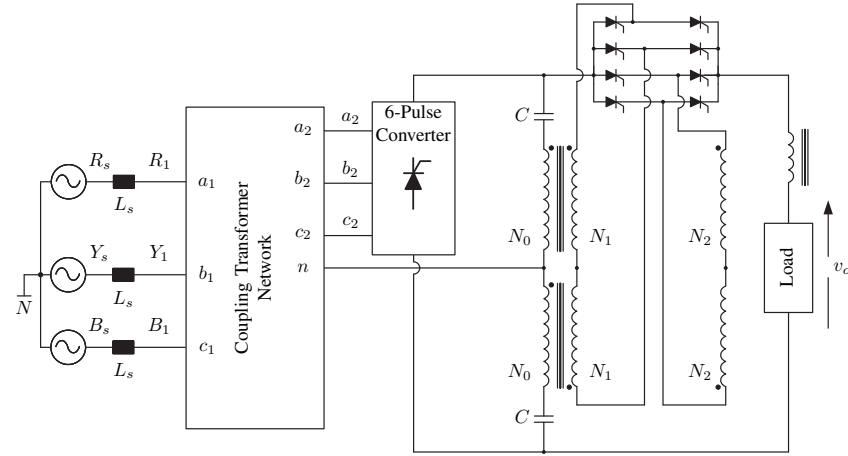

Fig. 17. Circuit configuration of six- to 24-pulse converter

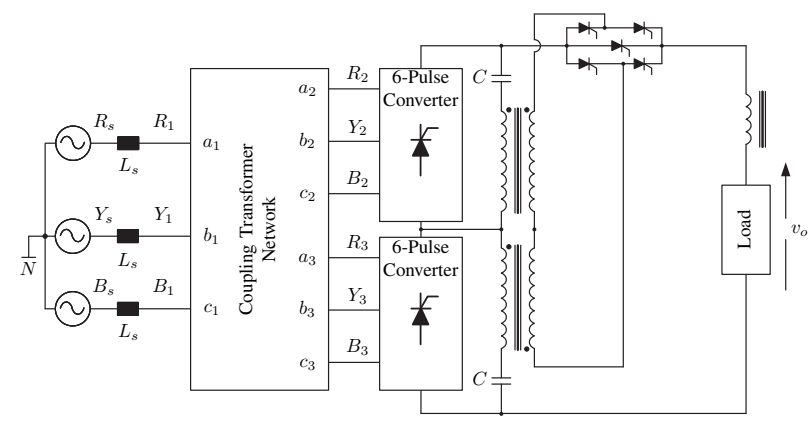

Fig. 18. Twelve- to 36-pulse converter

\section{ACKNOWLEDGMENT}

The authors would like to acknowledge the FONDECYT Regular 1160690 and Postdoctoral 3170014 research projects, MEC project number 80150056 as well as PROCIENCIA R\&D project 14-INV-097 for the economical support provided to develop this work.

\section{REFERENCES}

[1] N. Vazquez, H. Rodriguez, C. Hernandez, E. Rodriguez, and J. Arau, "Three-phase rectifier with active current injection and high efficiency," Industrial Electronics, IEEE Transactions on, vol. 56, no. 1, pp. 110119, 2009.

[2] A. F. Zobaa and S. H. E. A. Aleem, "A new approach for harmonic distortion minimization in power systems supplying nonlinear loads," IEEE Transactions on Industrial Informatics, vol. 10, no. 2, pp. 14011412, May 2014.

[3] A. Hamadi, S. Rahmani, and K. Al-Haddad, "A hybrid passive filter configuration for var control and harmonic compensation," IEEE Transactions on Industrial Electronics, vol. 57, no. 7, pp. 2419-2434, July 2010.

[4] F. Z. Peng, H. Akagi, and A. Nabae, "A new approach to harmonic compensation in power systems-a combined system of shunt passive and series active filters," IEEE Transactions on Industry Applications, vol. 26, no. 6, pp. 983-990, Nov 1990

[5] S. Bosch, J. Staiger, and H. Steinhart, "Predictive current control for an active power filter withlcl-filter," IEEE Transactions on Industrial Electronics, vol. 65, no. 6, pp. 4943-4952, June 2018.

[6] H. Akagi, "Active harmonic filters," Proceedings of the IEEE, vol. 93, no. 12, pp. 2128-2141, Dec 2005.

[7] S. Ostroznik, P. Bajec, and P. Zajec, "A study of a hybrid filter," IEEE Transactions on Industrial Electronics, vol. 57, no. 3, pp. 935-942, March 2010.

[8] J. W. Kolar and H. Ertl, "Status of the techniques of three-phase rectifier systems with low effects on the mains," in 21st International Telecommunications Energy Conference. INTELEC '99 (Cat. No.99CH37007), June 1999, p. 279.
[9] R. N. Beres, X. Wang, F. Blaabjerg, M. Liserre, and C. L. Bak, "Optimal design of high-order passive-damped filters for grid-connected applications," IEEE Transactions on Power Electronics, vol. 31, no. 3, pp. 2083-2098, March 2016.

[10] M. Rivera, D. Faundez, J. Kolar, P. Wheeler, J. Riveros, and S. Toledo, "Three-phase rectifiers with current compensation schemes - part II: Active and hybrid configurations," in 2018 International Conference on Electrical Systems for Aircraft, Railway, Ship Propulsion and Road Vehicles International Transportation Electrification Conference (ESARSITEC), Nov 2018.

[11] D. Paice, "Power electronics converter harmonics:multipulse methods for clean power," Wiley-IEEE Press Ebook Chapters, 1996.

[12] S. Choi, A. Von Jouanne, P. Enjeti, and I. Pitel, "Polyphase transformer arrangements with reduced kva capacities for harmonic current reduction in rectifier type utility interface," in Power Electronics Specialists Conference, 1995. PESC '95 Record., 26th Annual IEEE, vol. 1, 1995, pp. 353-359 vol.1.

[13] S. Choi, P. Enjeti, and I. Pitel, "Polyphase transformer arrangements with reduced kva capacities for harmonic current reduction in rectifiertype utility interface," Power Electronics, IEEE Transactions on, vol. 11, no. 5, pp. 680-690, 1996.

[14] T. Clark, F. Chivite-Zabalza, A. Forsyth, and M. Barnes, "Analysis and comparison of diode rectifier units suitable for aerospace applications," in Power Electronics, Machines and Drives, 2008. PEMD 2008. 4th IET Conference on, 2008, pp. 602-606.

[15] F. Chivite-Zabalza, A. Forsyth, and D. Trainer, "A simple, passive 24pulse ac-dc converter with inherent load balancing," Power Electronics, IEEE Transactions on, vol. 21, no. 2, pp. 430-439, 2006.

[16] F. Chivite-Zabalza, A. Forsyth, and I. Araujo-Vargas, "36-pulse hybrid ripple injection for high-performance aerospace rectifiers," Industry Applications, IEEE Transactions on, vol. 45, no. 3, pp. 992-999, 2009.

[17] F. Chivite-Zabalza, A. Forsyth, and I. Araujo-Vargas, "36-pulse hybrid ripple injection for high performance aerospace rectifiers," in Power Electronics and Drive Systems, 2007. PEDS '07. 7th International Conference on, 2007, pp. 591-598.

[18] J. Arrillaga and M. Villablanca, "24-pulse hvdc conversion," Generation, Transmission and Distribution, IEE Proceedings C, vol. 138, no. 1, pp. 57-64, 1991.

[19] B. Singh, G. Bhuvaneswari, and V. Garg, "Power-quality improvements in vector-controlled induction motor drive employing pulse multiplication in ac-dc converters," Power Delivery, IEEE Transactions on, vol. 21, no. 3, pp. 1578-1586, 2006.

[20] B. Singh, G. Bhuvaneswari, V. Garg, and S. Gairola, "Pulse multiplication in ac-dc converters for harmonic mitigation in vector-controlled induction motor drives," Energy Conversion, IEEE Transactions on, vol. 21, no. 2, pp. 342-352, 2006.

[21] J. Arrillaga and M. Villablanca, "A modified parallel hvdc convertor for 24 pulse operation," Power Delivery, IEEE Transactions on, vol. 6, no. 1, pp. 231-237, 1991

[22] Y. Liu, J. Arrillaga, and N. Watson, "Multi-level voltage sourced conversion by voltage reinjection at six times the fundamental frequency," Electric Power Applications, IEE Proceedings -, vol. 149, no. 3, pp. 201-207, 2002

[23] Y. Liu, J. Arrillaga, and N. Watson, "A new high-pulse voltage-sourced converter for hvdc transmission," Power Delivery, IEEE Transactions on, vol. 18, no. 4, pp. 1388-1393, 2003.

[24] M. Villablanca, W. Ziehlmann, C. Flores, C. Cuevas, and P. Armijo, "Harmonic reduction in adjustable-speed synchronous motors," Energy Conversion, IEEE Transactions on, vol. 16, no. 3, pp. 239-245, 2001.

[25] M. Villablanca, M. Arias, and C. Acevedo, "High-pulse series converters for hvdc systems," Power Delivery, IEEE Transactions on, vol. 16, no. 4, pp. 766-774, 2001. 